\title{
Maternal Characteristics and Temporal Trends in Birth Outcomes: Comparison between Spanish and Migrant Mothers
}

\author{
Carlos Varea, ${ }^{1}$ Cristina Bernis, ${ }^{1}$ and Antonio González González ${ }^{2}$ \\ ${ }^{1}$ Department of Biology, Faculty of Sciences, Autonomous University of Madrid, Darwin Street 2, 28049 Madrid, Spain \\ ${ }^{2}$ La Paz Maternal and Child Hospital, Faculty of Medicine, Autonomous University of Madrid, Arzobispo Morcillo Street 4, \\ 28029 Madrid, Spain
}

Correspondence should be addressed to Carlos Varea, carlos.varea@uam.es

Received 17 January 2012; Revised 13 March 2012; Accepted 14 March 2012

Academic Editor: Jacques Poot

Copyright () 2012 Carlos Varea et al. This is an open access article distributed under the Creative Commons Attribution License, which permits unrestricted use, distribution, and reproduction in any medium, provided the original work is properly cited.

\begin{abstract}
Low birth weight and preterm babies have been increasing in Spain since 1980, coinciding with important changes in the social and demographic structure of childbearing populations-including the contribution of a $25 \%$ of foreign mothers-and with increasing medical intervention in births. This study, based on 5,990,613 births, compares the temporary trends in reproductive patterns and birth outcomes in Spanish and foreign mothers during the period 1996-2009 and evaluates for the years 2007 to 2009 the relative contribution of mother's origin and Caesarean section to birth weight variability. Foreign mothers maintain their own reproductive pattern, whereas negative birth outcomes increase in all groups. Results from logistic regression analysis show that besides late maternity and primiparity also Caesarean section increases the risk for low birth weight. The reduction in Caesarean section rates between 2007 and 2009 might explain the reduction of low birth weight detected. A change of tendency simultaneously appears in most maternal and newborn characteristics, and in the mode of delivery in all ethnic groups since 2008. Coincidence in the timing of the change of trends points to a common factor. We suggest that the current world financial crisis could be this common cause, a hypothesis to be contrasted in future research.
\end{abstract}

\section{Introduction}

Low birth weight and preterm babies, which are widely used for assessing the health of populations, have been steadily increasing in Spain since 1980 [1] as in other Western countries. Population variability in birth outcomes and their temporal trends are closely related with the social and demographic changes in the structure of childbearing populations. European countries, including Spain, have experienced maximum decrease in fertility and a huge increase in the age of maternity [2], characterizing the so called "Second Demographic Transition" [3]. In Spain the reduction of fertility started later (1977) but occurred at a faster rate, reaching the lowest value in 1996 [4]. Nevertheless, whereas the decrease of fertility in Europe slows down and stabilises from the mideighties onwards, fertility in Spain inverts the trend and increases from 1997 to 2008, coinciding with a rapid increase of economic migrant women and men. Spain — which was a country of emigrants until the second half of the Twentieth Century-has become over the past twenty years a host nation for immigrants, most of which coming from South America, the Maghreb, and East Europe, whose populations are undergoing their specific demographic transitions [5]. The total increase in the absolute and relative figures for foreign women and their young age [6] explain the fact that the percentage of babies born in Spain from foreign mothers increased sevenfold in the last 15 years, from $3.1 \%$ in 1996 to a maximum of $21.0 \%$ in 2008 .

In Spain, as in other European countries, medicalization and intervention in pregnancy and delivery significantly increased from 1996 onwards [7]. Several authors [811] justify the need of extending medicalization of birth because of the rising rates in late maternal age, primiparity, and multiple pregnancies, which are associated with risky pregnancies and negative birth outcomes. Also the increasing proportion of deliveries by immigrant mothers might be also influencing negative birth outcomes. However, there is wide 
agreement among experts that medicalization of childbirth is excessive worldwide [12], and that, beside the changes in reproductive patterns and the increasing contribution of foreign populations, indicators of medicalization should be taken into account for a better comprehension of the current trends in birth outcomes.

Between 2005 and 2008 our group carried out research on the impact of migration on mother-infant health in Spain. Preliminary analyses focused on secular changes and ethnic variability in reproductive patterns $[13,14]$, and in low birth weight, preterm deliveries, and weight for gestational age [15-20] demonstrated ethnic differences in maternal and newborn characteristics. Spanish babies presented lower mean weight and higher frequency of low birth weight than those of migrant mothers, but similar rates of prematurity. Spanish mothers were older, more often primiparous, and have higher rates of multiple births compared with immigrants mothers. Finally, recent results [21, 22] reinforce the idea that increasing obstetric interventions might be contributing to the increasing trend of low birth weight and late preterm deliveries in Spain, where Caesarean section rates and other medical interventions during birth are in the highest range among European countries [7].

From 2007 onwards, national data on Caesarean section began to be included in the Statistical Bulletin of Childbirth, providing the opportunity to analyze for the trend in Caesarean section's rate at the national level and its contribution to explain the variability in birth weight. This study describes and compares the temporary trends in reproductive patterns and birth outcomes in Spanish and foreign mothers during the period 1996-2009 and evaluates for the years 2007 to 2009 the relative contribution of mother's origin and Caesarean section on the variability of birth weight, after adjusting for other maternal and newborn variables.

\section{Material and Methods}

The results presented in this study are based on the analyses of the almost six million births $(N=5,990,613)$ in Spain between 1996 and 2009. This information comes from the Boletín Estadístico de Parto (Statistical Bulletin of Childbirth, SBC), a register of all births-whatever the nationality or legal status of residence of the parents - which is used to prepare national vital statistics on birth. Using the original annual archives of microdata in ASCII, a single database was created for the period concerned, which was then analyzed using the statistics programme SPSS-19. The SBC has been successively updated since 1975 . For single births, it includes 98 variables about the parents, type of birth, and the newborn. Since 1996 the SBC includes the mother's country of birth and her nationality and since 2007 also includes additional socioeconomic variables about the parents and on the type of birth, specifically the incidence of Caesarean section.

In the present study reproductive patterns and birth outcome have been compared between Spanish and the three predominant groups of foreign mothers in Spain: South
Americans, Maghrebians, and Eastern Europeans. As indicated, maternal and paternal country of origin and current nationality are included in the SBC. In this paper, the term foreign refers to nonnative women (immigrants without the Spanish nationality, whatever their legal status of residence in the country) that became mothers in Spain. Table 1 shows the contribution made by these three predominant groups of foreign mothers in Spain to the total number of births in the country for the selected years 1996, 2002, and 2009. Considering only foreign mothers, the contribution of Maghrebian mothers to migrant births remain rather stable over the 15 years considered (27.2\% in 2009), South Americans have doubled their contribution (14.6\% in 1996 to $28.3 \%$ in 2009), and Eastern Europeans have increased nearly tenfold (from $1.8 \%$ to $16.8 \%$ ). As for the main nationalities within the three established groups of foreign mothers, Moroccan women are predominant among the Maghrebians (over 93\% all period considered), contributing with the $25.8 \%$ of all newborns from migrant mothers in 2009. Among Eastern Europeans, Romanians are the main national group, overtaking Polish women from 2000 onwards [23] and accounting for the $11.9 \%$ of foreign births in 2009 . Finally, Ecuadorian mothers are predominant among South Americans since 1998, and their contribution to migrant births was $8.1 \%$ in 2009 .

First, the temporal trends in reproductive patterns (age at first maternity, parity, first birth interval) and in birth outcome (multiplicity, maturity, birth weight) are described according to mother's origin for the period 1996-2009. Birth intervals between successive live births have been estimated based on their respective date of birth. Because the rate of preterm low birth weight and Caesarean sections is significantly higher in multiple births, and the rates of multiple births are much higher among the Spanish mother, only single births have been included in the figures comparing ethnic differences in the temporal trends for prematurity, low birth weight, and mean birth weight.

The second part of the paper is restricted to the period 2007-2009, for which-as previously indicated-the SBC includes information on the mode of delivery (Caesarean section yes/no), which allows to evaluate simultaneously the relative contribution of mother's origin and Caesarean section on the variability of birth weight after adjusting for other maternal and newborn variables. A logistic regression analysis has been carried out to evaluate the contribution of mother's ethnicity and Caesarean section on variability of birth weight after adjusting for year of birth, age at maternity ( $<20,20-27,28-34$ and $>34$ years), parity (primiparous/multiparous), sex of live birth, maturity (full term/preterm), and mother's occupation (professionals; skilled workers; primary and tertiary sectors, and nonskilled workers; nonworking mothers). A random 10\% sample has been used for this analysis.

The original data for the totality of the period studied corresponding to the findings shown in the figures has been included in the tables in the Supplementary Material available online at doi:10.1155/2012/412680 together with their respective statistics. 
TABLE 1: Origin distribution of mothers (Spain, selected years, all births).

\begin{tabular}{lccccc}
\hline $\begin{array}{l}\text { Year of } \\
\text { birth }\end{array}$ & Spain & $\begin{array}{c}\text { South } \\
\text { America }\end{array}$ & Maghreb & $\begin{array}{c}\text { East } \\
\text { Europe }\end{array}$ & $\begin{array}{c}\text { Other } \\
\text { areas }\end{array}$ \\
\hline \multirow{2}{*}{1996} & 96.9 & 0.5 & 0.8 & 0.1 & 1.9 \\
& $(347.553)$ & $(1.718)$ & $(2.825)$ & $(215)$ & $(6.998)$ \\
2002 & 89.4 & 4.2 & 2.3 & 1.0 & 3.1 \\
& $(368.148)$ & $(17.266)$ & $(9.431)$ & $(4.247)$ & $(12.953)$ \\
2009 & 79.1 & 5.9 & 5.7 & 3.5 & 5.8 \\
& $(384.480)$ & $(28.785)$ & $(27.656)$ & $(17.063)$ & $(28.143)$ \\
\hline \multirow{2}{*}{ Total } & 87.8 & 3.9 & 2.9 & 1.7 & 3.6 \\
& $(5.261 .597)$ & $(233.064)$ & $(175.577)$ & $(102.445)$ & $(217.930)$ \\
\hline
\end{tabular}

\section{Results}

3.1. Temporal Trends (1996-2007) in Maternal Reproductive Patterns by Mother's Origin: Age at First Maternity, Parity, and First Birth Interval. Significant differences in average age at first maternity according to mother's origin persist throughout the analyzed period, although trends change in 2008 (Figure 1). Spanish mothers maintain a sharp increase in average age at first maternity between 1996 and 2009, reaching an age over 30 years old. On the other hand, foreign mothers, who are younger at first maternity than Spanish mothers, share an increase in age at first maternity only from 2008 onwards.

Primiparous mothers are predominant in all four ethnic groups (Figure 2), but trends differ: primiparity has increased among Spanish mothers, whereas family sizes of two or more children have increased among the three immigrant groups, including the Eastern Europeans, who maintain the higher rate of primiparity.

Figure 3 shows the differences in the temporal trends for the mean first birth interval according to mother's origin. Spanish women show a steady decrease in the first interval, whereas South Americans and Eastern Europeans present a marked increase, and once more Maghrebians maintain a constant pattern, with the lowest mean interval between first and second live births. Trends for the second birth interval (not included) are similar to the first one.

3.2. Temporal Trends (1996-2007) in Birth Outcome by Mother's Origin: Multiparity, Maturity, and Birth Weight. During the period under study, over $99 \%$ of births took place with medical assistance in a maternity hospital.

Multiple births (Figure 4) significantly increased in all four groups between 2005 and 2007, although much more intensely among Spanish mothers, whose rates kept higher along the period. Again between 2007 and 2009 a sudden drop took place in the rate of multiple births in all ethnic groups, falling to the levels of 15 years ago among foreign mothers and reducing to half for Spanish mothers.

Gestational age and birth weight are the best and most widely used indicators of perinatal health. Prematurity (Figure 5) has increased significantly in all ethnic groups

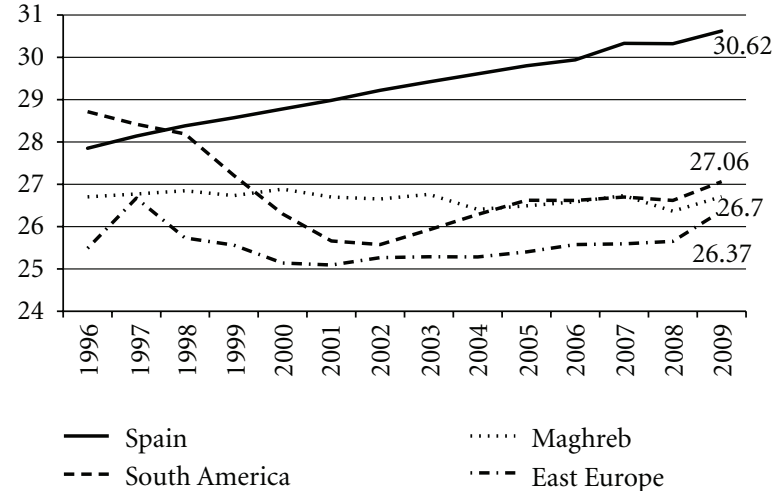

FIGURE 1: Temporal change in mean age at first maternity according to mother's origin (Spain, 1996-2009, all births).

throughout the analyzed period, more intensely between 2005 and 2007, being highest among Eastern European mothers. Nevertheless a change of tendency took place in 2008 for Spanish, Maghrebian, and South American mothers, and in 2009 for Eastern Europeans, who maintain the highest incidence.

Birth weight has been evaluated using both mean birth weight (Figure 6) and rate of low birth weight (Figure 7). Significant ethnic differences exist for both variables in figures and temporal trends. Newborns of Maghrebian mothers maintain a stable mean birth weight, which is the highest among the four ethnic groups. Newborn from Eastern European mothers also maintain a constant mean birth weight throughout the period, with higher values than those of the Spanish, who are the only ones experiencing a sharp and significant decrease in their mean birth weight between 1996 and 2009. Finally, live births from South American mothers show a marked rise in mean birth weight from 2001 onwards, reaching the values of those born from Maghrebian mothers. In spite of these significant differences in temporal trends in weight at birth, the incidence of low weight at birth clearly diverges from 2000 onwards, rising significantly in all four groups of mothers, especially among Spanish and Eastern Europeans, and more moderately among Maghrebians and South Americans. Again, coinciding with the tendencies shown by other reproductive and perinatal indicators, a substantial decrease of the rate of low birth weight (as well as a slight increase in the mean birth weight) has been detected in all four groups in 2008 and 2009.

The distribution of low birth weight between preterm and full term births (in single births) also differs among ethnic groups (Figure 8). Interestingly, Spanish and Maghrebian mothers show the highest incidence of low birth weight in full term deliveries between 1996 and 2007. Once again a new common tendency appears for all four groups in 2007, presenting a sharp decrease in the frequency of low birth weight among full term babies.

3.3. Effect of Mother's Origin and Medical Intervention (Caesarean Section) on Low Birth Weight after Adjusting for Year of Birth, Maternal, and Newborn Variables (2007-2009). Rates 


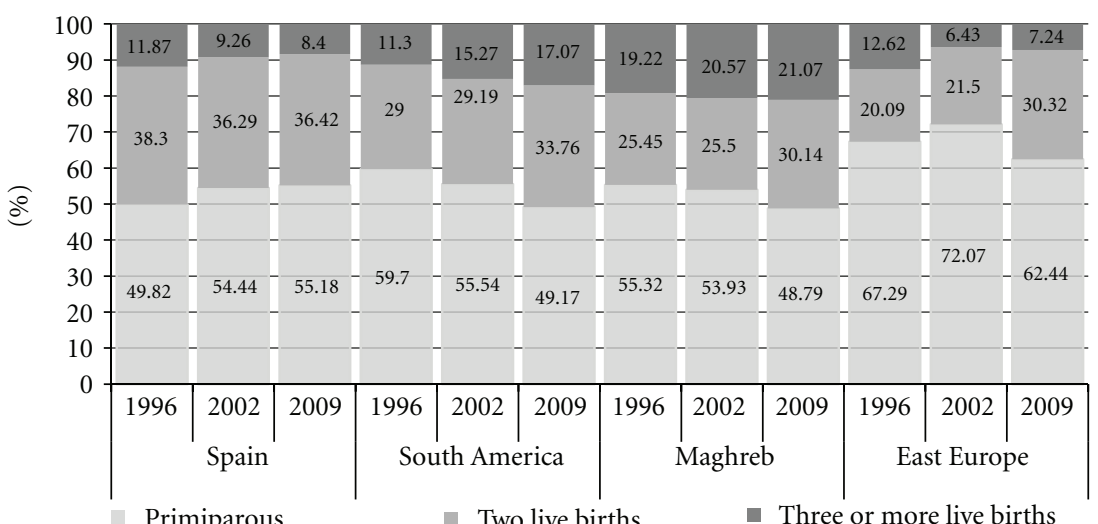

FIGURE 2: Temporal change in family size distribution according to mother's origin (Spain, selected years, all births).

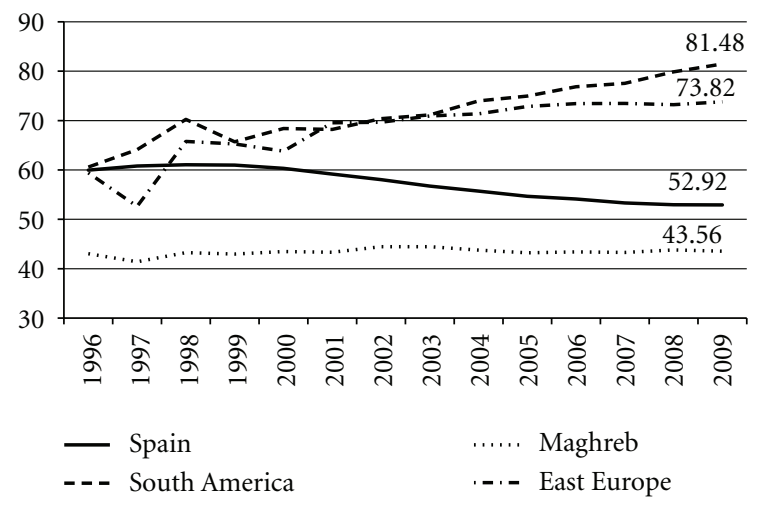

FIGURE 3: Temporal change in mean first birth interval according to mother's origin (Spain, 1996-2009, all births).

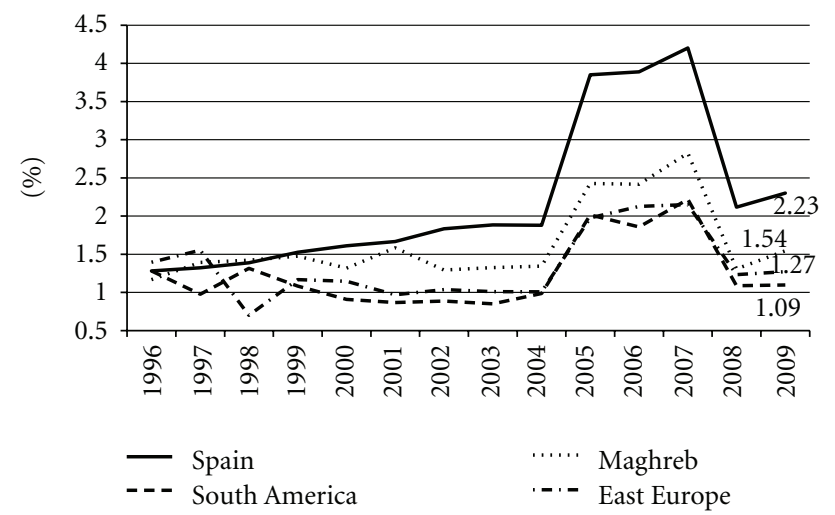

FIGURE 4: Temporal change in the rate of multiplicity according to mother's origin (Spain, 1996-2009, all births).

of Caesarean section are highest among South American and Spanish women and lowest for Eastern Europeans (Figure 9). Interestingly, the incidence of Caesarean sections markedly decreased in all groups between 2007 and 2009 (around 8$6 \%)$.

Table 2 summarizes the logistic regression analysis carried out to explain the contribution of mother's origin

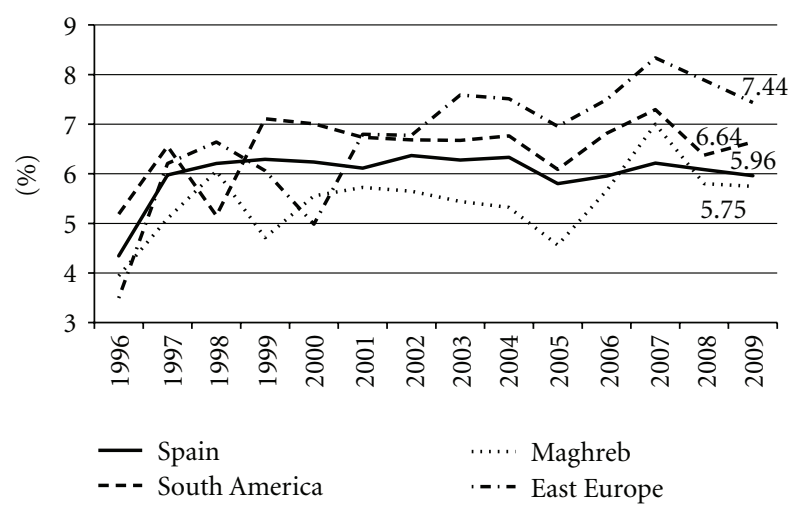

FIGURE 5: Temporal change in the rate of prematurity according to mother's origin (Spain, 1996-2009, single births).

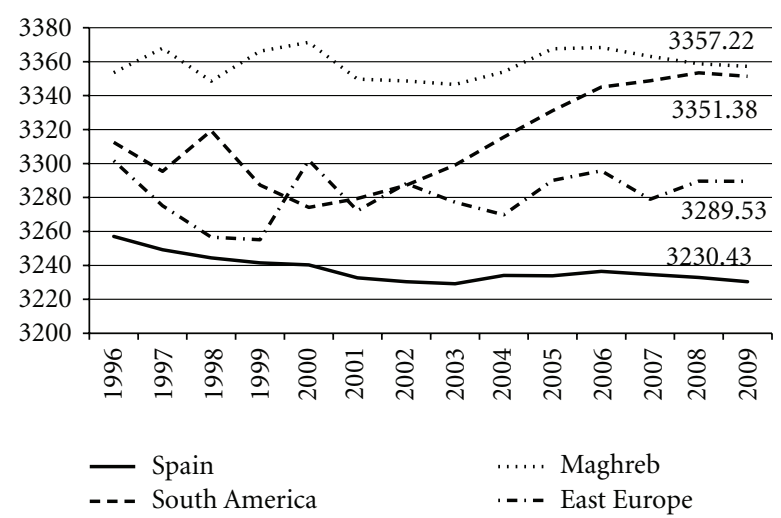

FIgure 6: Temporal change in mean birth weight according to mother's origin (Spain, 1996-2009, single births).

and medical intervention (Caesarean section yes/no), after adjusting for the year of birth, maternal social and reproductive characteristics, and maturity (all OR values and the 95\% CIs and $P$ values for all variables are presented in Table 2). The model explains $35,8 \%$ of variability in the birth weight. The outcome in terms of low birth weight (yes/no) was found to be significantly associated with all 


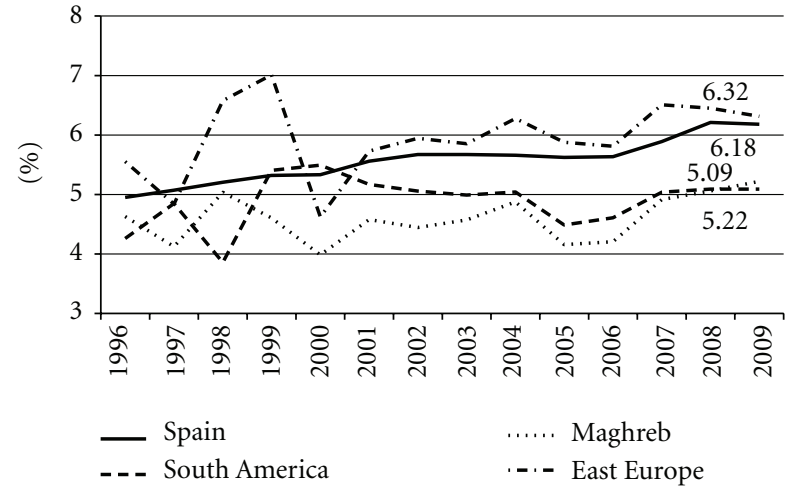

FIgURE 7: Temporal change in the rate of low birth weight according to mother's origin (Spain, 1996-2009, single births).

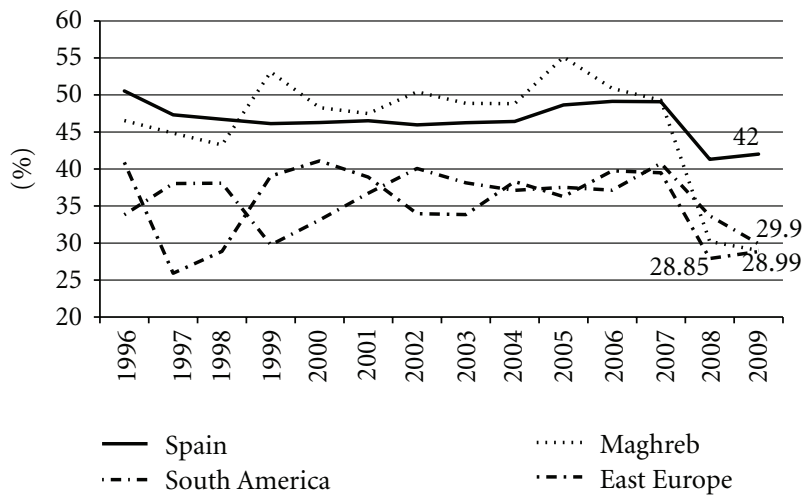

FIGURE 8: Temporal change in the percentage of low birth weight in full term deliveries on total live births according to mother's origin (Spain, 1996-2009, single births).

independent variables introduced in the model. Compared with the oldest age group $(>34)$, the risk of having low birth weight babies is significantly reduced for mothers aged 20-27 and 28-34 years, whereas adolescent mothers $(<20)$ do not show significant differences with the reference age group. Compared with the better-off women (professionals), the risk of having low birth weight babies is significantly increased for the other occupational groups. Primiparous women are at significant higher risk of having low birth weight babies when compared with multiparous. Compared with Spanish women, all the three groups of immigrant mothers present a significant lower risk of having low birth weight babies. Finally, Caesarean section interventions significantly increased the risk of having low birth weight babies.

\section{Discussion}

Immigration is a facet of economic globalisation and of cultural homogenisation which can introduce positive changes in reproductive behaviour and in perinatal care among women who emigrate. The most positive aspect of immigration is that it can accelerate the process of

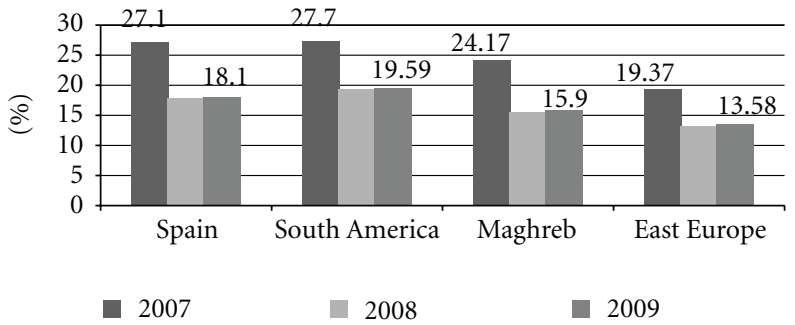

Figure 9: Temporal change in rate of Caesarean section on total births according to mother's origin (Spain, 2007-2009, single births).

equality, modernisation, and secularisation among immigrant groups, while also facilitating access to social and medical services and encouraging behaviour similar to that of the host nation. But migration is often associated with marginal situations, work exploitation, and loss of social family networks, which can negatively affect health. In Spain, for example, the number of checkups during pregnancy is lower among immigrants, who also tend to go to hospital at a more advanced stage of delivery [18]. Although maternal deaths are well under control, there are more cases among foreign mothers than Spanish ones [24]. Data from national vital records, such as those used in this study, clearly reflect socioeconomic, demographic and medical characteristics and allow simultaneous evaluation of temporal trends in reproductive patterns, certain medical interventions, and pregnancy outcomes [25-27]. Furthermore, the large number of cases allows for temporary analyses according to maternal origin.

This study has largely confirmed previous results, based both on population data and vital records [13, 20-22], which showed significant differences in reproductive patterns and perinatal characteristics between Spanish and immigrant mothers. Our findings also show that ethnic differences in reproductive patterns remain constant (or even increase) throughout the analyzed period, whereas the ethnic characteristics in mode of delivery and perinatal health converge with the predominant pattern of the Spanish mothers, despite still showing some quantitative differences.

During the analyzed period, Maghrebian and Eastern European mothers maintain a more stable reproductive pattern, whereas Spanish and South American mothers show a marked shift in their reproductive characteristics, although with opposing trends, having the Spanish mothers maintained a dramatic delay in the average age of first maternity. From 2007 the age at first maternity increases in all the immigrant groups, initiating a change of tendency similar to the Spanish. In contrast with this convergence in age at maternity, the foreign groups maintain different birth spacing patterns: South American and Eastern European mothers have progressively delayed a second pregnancy, whereas Maghrebians maintain the shortest birth spacing. Immigrant women have increased their family size, even the Eastern European mothers, who are the youngest and predominantly primiparous. Maghrebian mothers show a 
TABLE 2: Results of the logistic regression analysis explaining the relative contribution of mother's origin and Caesarean section to birth weight variability (Spain, 2007-2009, single births).

Low birth weight $(<2.500 \mathrm{~g})$

Newborn, labor, and maternal characteristics

2007-2009

(reference category)

\begin{tabular}{|c|c|c|c|}
\hline & \multirow{2}{*}{$\operatorname{Exp}(B)$} & \\
\hline & & $\begin{array}{l}\text { Lower } \\
\text { limit }\end{array}$ & $\begin{array}{l}\text { Upper } \\
\text { limit }\end{array}$ \\
\hline Year of birth & $1.095^{* * *}$ & 1.056 & 1.135 \\
\hline \multicolumn{4}{|l|}{ Occupation (professionals) } \\
\hline Skilled workers & $1.109^{*}$ & 1.015 & 1.212 \\
\hline Primary and tertiary sectors, and non-skilled workers & $1.267^{* * *}$ & 1.164 & 1.380 \\
\hline Housewives and students & $1.408^{* * *}$ & 1.287 & 1.541 \\
\hline \multicolumn{4}{|l|}{ Origin (Spain) } \\
\hline South America & $.673^{* * *}$ & .591 & .768 \\
\hline Maghreb & $.621^{* * *}$ & .530 & .728 \\
\hline East Europe & $.716^{* *}$ & .606 & .845 \\
\hline \multicolumn{4}{|l|}{ Maternal age ( $>34$ years) } \\
\hline$<20$ years & ns & 1.015 & 1.212 \\
\hline $20-27$ years & $.851^{* *}$ & .775 & .933 \\
\hline $28-34$ years & $.902^{* *}$ & .841 & .967 \\
\hline \multicolumn{4}{|l|}{ Parity (primiparous) } \\
\hline Multiparous & $.698^{* * *}$ & .655 & .743 \\
\hline \multicolumn{4}{|l|}{ Sex (male) } \\
\hline Female & $1.507^{* * *}$ & 1.422 & 1.598 \\
\hline \multicolumn{4}{|l|}{ Maturity (full term) } \\
\hline Preterm & $45.458^{* * *}$ & 42.680 & 48.205 \\
\hline \multicolumn{4}{|l|}{ Caesarean section (No) } \\
\hline Yes & $1.564^{* * *}$ & 1.465 & 1.669 \\
\hline
\end{tabular}

remarkable stability in their reproductive pattern and the highest fertility rate among all immigrant women.

Summing up, after 15 years of migration there has not been convergence between the reproductive patterns of the migrant groups and the Spanish population; furthermore, divergences have been detected for most reproductive variables. Cultural factors, including religion, language, and gender relationships greatly influence reproductive decisions. In a previous publication also based in national statistics [13], the rate of marriages/unions between couples of the same country was evaluated. Results showed that marriages mainly occur among men and women from the same country or geographic area, especially so among Maghrebians, a fact that undoubtedly contributes to the preservation of their reproductive norms.

Regarding variability in birth outcome and its temporal trends, for most of the Twentieth Century perinatal health was directed towards reducing the death rate among mothers and newborns, an effort that was highly successful and resulted in very few cases of perinatal death, as is the case in Spain. However, once mortality rates are under control, perinatal health should be geared towards functional improvements for neonates, which, according to WHO [12, page 14], involves achieving (in terms of public health) "optimal foetal development [...] defined as that state at birth in which the neonate is most likely to survive and thrive through the neonatal transition and infancy, and to be prepared such that early developmental effects do not impact negatively on the individual's life-course." However, the increasing rates in premature births and low birth weight which occur both in wealthy and developing countries [7, 28-31] are a clear suggestion that something is not working in preventative neonatal healthcare. Some authors consider that the change in the reproductive patternsnamely, delayed age at first maternity-is to a great extent responsible for these increase in adverse birth outcomes, and also for an increasing need for intervention in deliveries, especially Caesarean sections $[7,9,11,32]$. However, different publications suggest that beside maternal age, extensive unnecessary medical intervention in delivery might also be playing an important role [7, 22, 33].

Spanish mothers not only present the lowest average birth weight babies and the highest rates of low birth weight, but also share with the Maghrebian mothers the highest frequency of low birth weight among full term births, which is more typical of developing populations [34]. This situation, in which groups in worst social situations, such as migrants, present better perinatal health when compared to nationals 
from the host country, was previously found in the USA, especially among Mexicans [35-37], and in several European countries, including Spain $[13,17,20,38-40]$. Linking these results with those of the logistic regression for the period 2007-2009, which show that migrant mothers are at a significant lower risk of having low birth weight compared with the Spanish, allow to conclude that immigrant mothers have not been contributing to the increase of low birth weight in Spain.

Despite these quantitative differences, all ethnic groups share, with small time lags, the same temporal trends of increasing multiple birth, low birth weight, and preterm births, with a maximum between 2005 and 2007, and a decrease thereafter. The fact that mothers with very distinctive reproductive patterns and differences in birth outcome share these tendencies strengthens the idea that medical practices might be influencing the incidence in preterm and low birth weight babies.

In Spain, as in other European countries [1,7], medicalization and intervention in pregnancy and delivery significantly increased during the last fifteen years, existing wide agreement among experts that there is an excessive medicalization in childbearing. Results from logistic regression also suggest that, besides of the rising rates in late maternal age and primiparity, which are associated with risky pregnancies and negative birth outcomes, also the excessive incidence of a series of interventions in labor (namely, Caesarean section) might be contributing to the observed changes in low birth weight.

Since 2007 a reduction in Caesarean section rates is shared by all ethnic groups, together with an increase in maternal age and a decrease in multiple births, in prematurity, and in low birth weight in full term deliveries. Particularly interesting is the striking 9\% reduction in the rate of Caesarean sections in only three years (from 26.7\% in 2007 to $17.9 \%$ in 2009 , all births considered), after being continuously on the rise since the late eighties. The reasons for this reduction need further investigation after more than 30 years of unsuccessful recommendations by international organizations, and the national institutions and the obstetrical and gynaecological societies [7, 28, 41-43], as well as after hundreds of publications insisting on the need to reduce unnecessary medical intervention during birth, specially induced births and Caesarean sections. All these calls have met with little success because over that period of time medicalization of births has continued to increase in most populations, including Spain up to 2008 [1, 7, 42].

The simultaneous decreases in multiple births, Caesarean section, premature, and low birth weight in full term births together with increased maternal age, suggests that a common factor could be affecting them all, and we suggest that the current world financial crisis, which is strongly affecting Spain, could be this common cause. This hypothesis requires a more detailed analysis and follow-up, and a deep reflection on the possible trade-offs of the economic crisis on maternal and perinatal health. The recent European perinatal health report [7] recommends optimising the benefits of new technology and universal medical assistance during pregnancy and birth, while at the same time reducing the negative effects, particularly those which affect most women whose pregnancies are not problematic. Considering the current economic crisis, the reverse situation must be foreseen in order to ensure that all mothers and neonates with specific health needs or risks are appropriately covered.

\section{Acknowledgment}

This paper has been prepared as a part of the research project The Impact of Migration on Maternal-Infant Health from a Gender Perspective, funded by I + D + I National Plan (20062008), Exp. 06/31, Ministerio de Sanidad y Política Social (Spain).

\section{References}

[1] Ministerio de Sanidad y Consumo de España, "Estrategia de atención al parto normal en el Sistema Nacional de salud," 2007, http://www.msc.es/organizacion/sns/planCalidadSNS/ pdf/equidad/estrategiaPartoEnero2008.pdf.

[2] F. C. Billari, A. C. Liefbroer, and D. Philipov, "The postponement of childbearing in Europe: driving forces and implications," Vienna Yearbook of Population Research, pp. 117, 2006.

[3] D. J. van de Kaa, "Europe's second demographic transition," Population Bulletin, vol. 42, no. 1, pp. 1-59, 1987.

[4] INE, Instituto Nacional de Estadística, 2012, http://www.ine .es/.

[5] World Health Organization, Health Statistics, World Health Organization, Geneva, Switzerland, 2011.

[6] INE, Mujeres y Hombres en España 2010, Instituto Nacional de Estadística y Ministerio de Igualdad, Madrid, Spain, 2010.

[7] EURO-PERISTAT, "European perinatal health report," EURO-PERISTAT Project, with SCPE, EUROCAT \& EURONEOSTAT, 2008, http://www.europeristat.com/our-publications/european-perinatal-health-report.html.

[8] C. Wilkinson, G. McIlwaine, C. Boulton-Jones, and S. Cole, "Is a rising caesarean section rate inevitable?" British Journal of Obstetrics and Gynaecology, vol. 105, no. 1, pp. 45-52, 1998.

[9] P. Astolfi, L. Ulizzi, and L. A. Zonta, "Selective cost of delayed childbearing," Human Reproduction, vol. 14, no. 2, pp. 572$573,1999$.

[10] K. S. Joseph, D. C. Young, L. Dodds et al., "Changes in maternal characteristics and obstetric practice and recent increases in primary cesarean delivery," Obstetrics \& Gynecology, vol. 102, no. 4, pp. 791-800, 2003.

[11] C. J. Machado, "Impact of maternal age on birth outcomes: a population-based study of primiparous Brazilian women in the city of São Paulo," Journal of Biosocial Science, vol. 38, no. 4, pp. 523-535, 2006.

[12] World Health Organization, "Promoting optimal fetal development: a report of a Technical Consultation," 2006, http://www.who.int/nutrition/publications/fetal_dev_report_ EN.pdf.

[13] C. Varea, "El debate sobre un nuevo patrón reproductor en España y la contribución del colectivo de mujeres emigrantes," in Determinantes Biológicos, Psicológicos y Sociales de la Maternidad en el S XXI. Mitos y Realidades, C. Bernis, P. R. López, and P. Montero, Eds., pp. 303-315, Universidad Autónoma de Madrid, Madrid, Spain, 2009. 
[14] C. Varea, C. Bernis, and P. Montero, "Cambio reproductivo y espaciamiento en mujeres españolas, 1987-2007," in Diversidad Humana y Antropología Aplicada, E. Gutiérrez-Redomero, Á. Sánchez, and V. Galera, Eds., pp. 303-315, Universidad de Alcalá de Henares, Madrid, Spain, 2010.

[15] C. Bernis, "Determinantes biológicos y culturales del peso al nacer en España 2000: valoración en hijos de mujeres inmigrantes y no inmigrantes," Antropo, vol. 10, no. 1, pp. 6173, 2005.

[16] P. Acevedo, "Impacto socio-sanitario de la migración en las mujeres magrebíes y latinoamericanas en Madrid," Revista Cubana de Salud Pública, vol. 31, no. 3, pp. 92-201, 2005.

[17] C. Bernis and C. Varea, "Comportamientos reproductores y peso al nacer: análisis en los colectivos marroquí y español," in Diversidad Biológica y Salud Humana, A. Martínez-Almagro, Ed., pp. 279-288, Universidad Católica de Murcia, Murcia, Spain, 2006.

[18] C. Bernis, "Determinantes biológicos y sociales del embarazo y el parto: estado nutricional, género y origen," in Determinantes Biológicos, Psicológicos y Sociales de la Maternidad en el S XXI. Mitos y Realidades, C. Bernis, P. R. López, and P. Montero, Eds., pp. 79-124, Universidad Autónoma de Madrid, Madrid, Spain, 2009.

[19] P. Acevedo, C. Bernis, C. Varea, and P. Montero, "Gestación y maternidad de las mujeres de Madrid: comparación entre madres inmigrantes y españolas," Revista Española de Antropología Física, vol. 30, no. 1, pp. 23-30, 2009.

[20] C. Bernis, "Factores causales de la reducción del peso al nacer en España 1980-2007: cambios en la viabilidad fetal, en la distribución de la edad gestacional y en la dinámica del crecimiento intrauterino," Revista Española de Antropología Física, vol. 31, no. 1, pp. 233-247, 2010.

[21] C. Bernis and C. Varea, "Hour of birth and birth assistance: from a primate to a medicalized pattern?" American Journal of Human Biology, vol. 24, no. 1, pp. 14-21, 2012.

[22] C. Bernis, C. Varea, P. Acevedo, and B. Bogin, "Labor management and birth outcome among migrant and Spanish women in Madrid: does the variability reflect differences in obstetric decisions according to ethnic origin?" Maternal and Child Health Journal. In press.

[23] S. Marcus, "Romanian migration to the Community of Madrid (Spain): patterns of mobility and return," International Journal of Population Research, vol. 2011, Article ID 258646, 13 pages, 2011.

[24] M. A. Luque Fernández, A. B. Cavanillas, and S. de Mateo, "Excess of maternal mortality in foreign nationalities in Spain, 1999-2006," European Journal of Obstetrics Gynecology and Reproductive Biology, vol. 149, no. 1, pp. 52-56, 2010.

[25] E. Alberman, "Are our babies becoming bigger?" Journal of the Royal Society of Medicine, vol. 84, no. 5, pp. 257-260, 1991.

[26] C. L. Roberts and P. A. L. Lancaster, "Australian national birthweight percentiles by gestational age," Medical Journal of Australia, vol. 170, no. 3, pp. 114-118, 1999.

[27] S. W. Wen, M. S. Kramer, R. Platt et al., "Secular trends of fetal growth in Canada, 1981 to 1997," Paediatric and Perinatal Epidemiology, vol. 17, no. 4, pp. 347-354, 2003.

[28] World Health Organization, "Pregnancy, childbirth, postpartum and newborn care: a guide for essential practice," 2006, http://whqlibdoc.who.int/publications/2003/ 924159084X.pdf.

[29] M. S. Kramer, R. Platt, H. Yang et al., "Secular trends in preterm birth: a hospital-based cohort study," Journal of the
American Medical Association, vol. 280, no. 21, pp. 1849-1854, 1998.

[30] R. Romero, J. Espinoza, J. P. Kusanovic et al., "The preterm parturition syndrome," BJOG, vol. 113, no. 3, pp. 17-42, 2006.

[31] M. Lampl, J. P. Kusanovic, O. Erez et al., "Early rapid growth, early birth: accelerated fetal growth and spontaneous late preterm birth," American Journal of Human Biology, vol. 21, no. 2, pp. 141-150, 2009.

[32] V. Fuster, "Riesgos asociado en el retraso en la maternidad," in Determinantes Biológicos, Psicológicos y Sociales de la Maternidad en el S XXI. Mitos y Realidades, C. Bernis, P. R. López, and P. Montero, Eds., pp. 298-317, Universidad Autónoma de Madrid, Madrid, Spain, 2009.

[33] E. F. C. Murta, G. C. Freire, D. C. Fabri, and R. H. Fabri, "Could elective cesarean sections influence the birth weight of full-term infants?" Sao Paulo Medical Journal, vol. 124, no. 6, pp. 313-315, 2006.

[34] United Nations Children's Fund and World Health Organization, "Low birth weight. Country, regional, and global estimates," 2004, http://www.unicef.org/publications/ files/low_birthweight_from_EY.pdf.

[35] P. Buekens, G. Masuy-Stroobant, and T. Delvaux, "High birthweights among infants of North African immigrants in Belgium," American Journal of Public Health, vol. 88, no. 5, pp. 808-811, 1998.

[36] J. B. Gould, A. Madan, C. Qin, and G. Chavez, "Perinatal outcomes in two dissimilar immigrant populations in the United States: a dual epidemiologic paradox," Pediatrics, vol. 111, no. 6, pp. e676-e682, 2003.

[37] A. Cervantes, L. Keith, and G. Wyshak, "Adverse birth outcomes among native-born and immigrant women: replicating national evidence regarding Mexicans at the local level," Maternal and Child Health Journal, vol. 3, no. 2, pp. 99-109, 1999.

[38] C. Prado, F. Rovillé-Susse, and P. Acevedo, "État nutritionnel des femmes enceintes d'origine maghrébine et de leurs nourrissons: la situation en France et en Espagne," Antropo, vol. 7, pp. 139-144, 2004.

[39] P. Acevedo, Las mujeres inmigrantes del Magreb y América Latina en la Comunidad de Madrid: características sociales y sanitarias, Ph.D. thesis, Universidad Autónoma de Madrid, Madrid, Spain, 2004.

[40] A. Vahratian, P. Buekens, T. Delvaux, M. Boutsen, Y. Wang, and L. L. Kupper, "Birthweight differences among infants of North African immigrants and Belgians in Belgium," European Journal of Public Health, vol. 14, no. 4, pp. 381-383, 2004.

[41] P. Lumbiganon, M. Laopaiboon, A. M. Gülmezoglu et al., "Method of delivery and pregnancy outcomes in Asia: the WHO global survey on maternal and perinatal health 200708," The Lancet, vol. 375, no. 9713, pp. 490-499, 2010.

[42] Ministerio de Sanidad y Política Social de España, "Guía de práctica clínica sobre la atención al parto normal,” 2010, http://www.msc.es/organizacion/sns/planCalidadSNS/pdf/equidad/guiaPracticaClinicaParto.pdf.

[43] Sociedad Española de Obstetricia y Ginecología, "Recomendaciones sobre la asistencia al parto," 2008, http://www.sego.es/ Content/pdf/20080117_recomendacion_al_parto.pdf. 


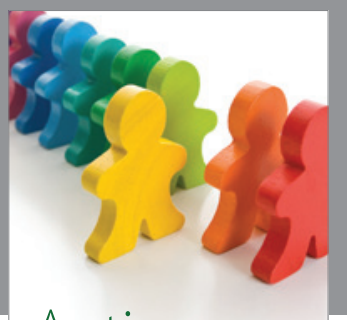

Autism

Research and Treatment
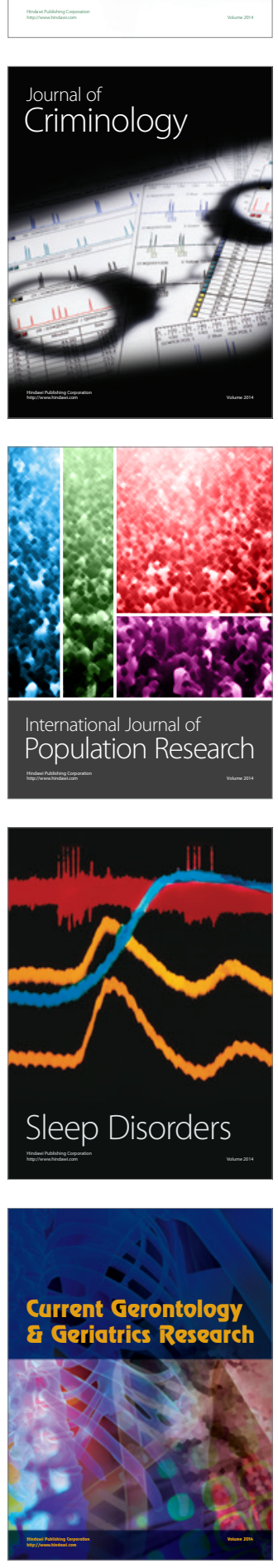
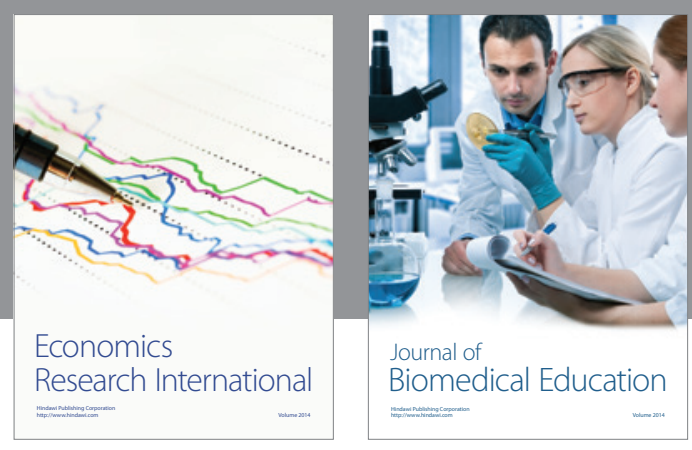

Journal of

Biomedical Education

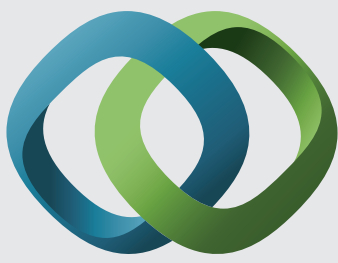

\section{Hindawi}

Submit your manuscripts at

http://www.hindawi.com
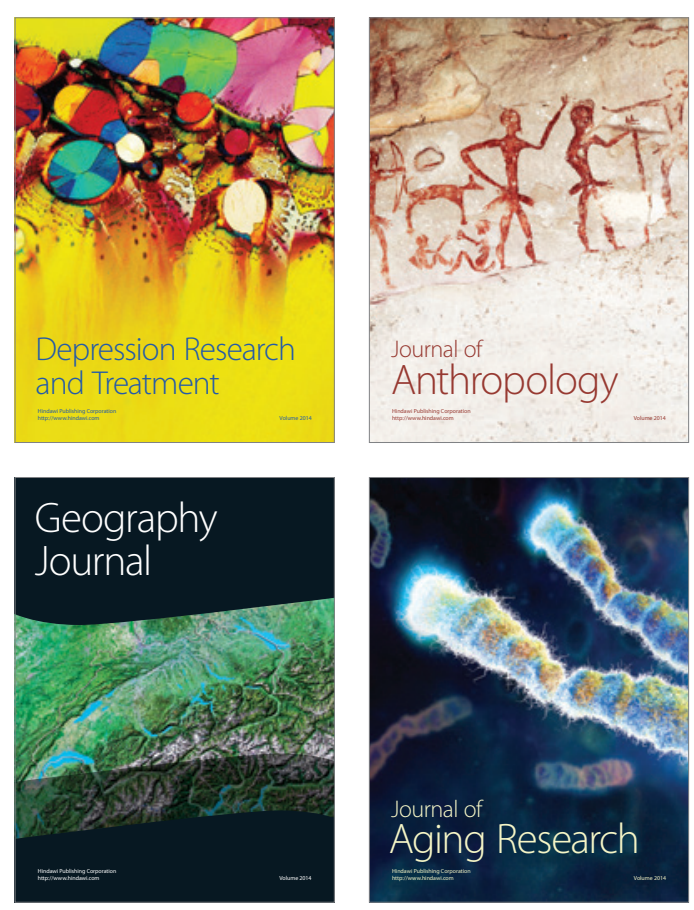

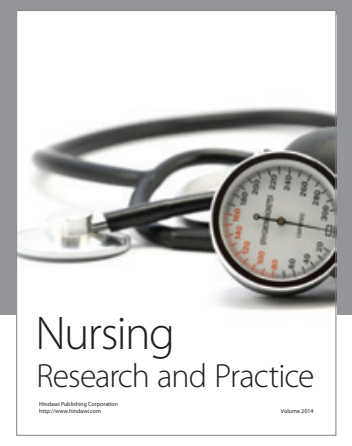

Nursing

Research and Practice

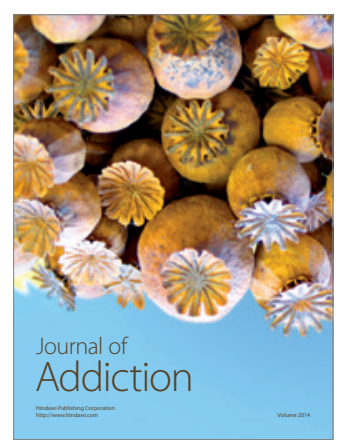

Child Development

Research

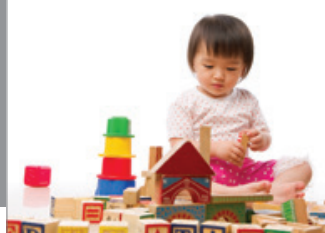

迥
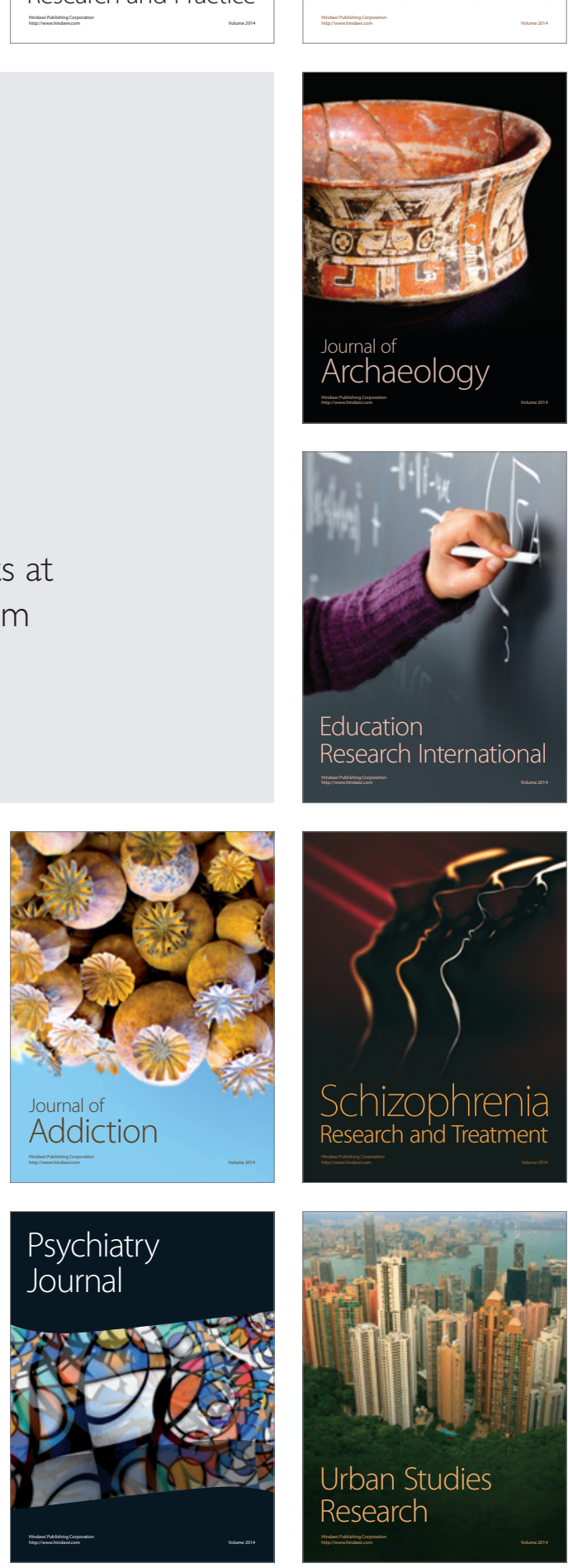